\title{
IMAGING THE GENETICS OF EXECUTIVE FUNCTION
}

Ciara M. Greene ${ }^{1,2}$, Wouter Braet ${ }^{1}$, Katherine A. Johnson ${ }^{1,2}$ \& Mark A. Bellgrove . $^{3}$

1) Trinity College Institute of Neuroscience, Trinity College Dublin, Ireland

2) Neuropsychiatric Genetics Group, Department of Psychiatry, Trinity College

Dublin, Ireland

3) School of Psychology and Queensland Brain Institute, University of

Queensland, Australia

Correspondence should be addressed to Ciara Greene (cmgreene@gmail.com)

Acknowledgements: This work was supported by grants from the Irish Health Research Board, Science Foundation Ireland and the Irish Higher Education Authority's

Programme for Research in Third-Level Institutions. KAJ is supported by the Health Research Board of Ireland. 


\section{Abstract}

Recent advances in neuroimaging technologies have allowed ever more detailed studies of the human brain. The combination of neuroimaging techniques with genetics may provide a more sensitive measure of the influence of genetic variants on cognitive function than behavioural measures alone. Here we present a review of functional magnetic resonance imaging (fMRI) studies of genetic links to executive functions, focusing on sustained attention, working memory and response inhibition. In addition to studies in the normal population, we also address findings from three clinical populations: schizophrenia, ADHD and Autism Spectrum Disorders. While the findings in the populations studied do not always converge, they all point to the usefulness of neuroimaging techniques such as fMRI as potential endophenotypes for parsing the genetic aetiology of executive function. 


\section{Introduction}

The abilities to control and inhibit action and to use memory to guide future behaviour are fundamental aspects of human cognition that allow us to function successfully in complex environments. In evolutionary terms, the development of such "executive" capacities has in large part paralleled the development of the frontal lobe of the human brain. It is perhaps unsurprising that individual differences in executive capacity may be attributed, at least in part, to genetic variation (see Goldberg \& Weinberger, 2004 for a review) Inroads to studying the genetic underpinnings of neuronal processes underlying executive functions have traditionally been made by investigating hereditary disorders characterised by deficits in these processes. Technological advances have meant that the effects of allelic variation in genes involved in neurotransmission can now be partially observed using neuroimaging techniques such as magnetic resonance imaging (MRI). This review draws on findings from both genetics and neuroimaging in an effort to elucidate our current understanding of the influence of genetic variants on the neuropsychology of healthy and psychiatric populations.

For the purposes of this review, we focus on three executive functions and their genetic and neurological correlates: sustained attention, working memory and response inhibition. We focus on studies of three heritable psychiatric disorders, namely attention deficit hyperactivity disorder (ADHD), autism and schizophrenia, and compare findings from these disorders with studies of normal populations in an attempt to clarify the genetics of executive function. Although a body of research has addressed the impact of genetic factors on morphological changes in these orders, the implications of these findings are beyond the scope of this review, and we limit ourselves to a discussion of functional MRI studies. 


\section{Disorders}

\section{Schizophrenia}

\section{Symptoms}

Schizophrenia is characterised by a large variety of symptoms, usually subdivided into 'positive' (e.g. hallucinations, delusions) and 'negative' (e.g. flattening of affect, apathy, poverty of speech) symptoms (see Capuano et al., 2002 for an overview).

\section{Executive function deficits}

Deficits in a broad range of executive functions are commonly seen in schizophrenia (Goldberg et al., 2003). A large body of research has shown that participants with schizophrenia routinely perform poorly on the Wisconsin Card Sorting Test (WCST), one of the most common tests of executive function (see Heinrichs \& Zakzanis, 1998 for a review). The performance of patients with schizophrenia in different aspects of executive function has been independently assessed, and deficits have been observed in tests of sustained attention (Heinrichs \& Zakzanis, 1998), working memory (Heaton et al., 2001), conflict resolution (Wang et al., 2005) and response inhibition (Badcock et al., 2002) .

\section{Genetic evidence}

Schizophrenia is known to be highly heritable, with estimates ranging from $68-89 \%$ (Jones and Cannon 1998; National Institute of Mental Health's Genetics Workgroup, 1998). The cognitive deficits of the disorder also appear to have a heritable component, with unaffected siblings of schizophrenic patients displaying inferior performance on the WCST compared with controls (Egan, Goldberg, Gscheidle et al., 2001). A frequently expressed view is that schizophrenia is the result of specific variation in a large number of genes, each with small effect (Risch \& Rao, 1990).

\section{ADHD}

Symptoms 
Attention deficit hyperactivity disorder (ADHD) is a common childhood-onset psychiatric condition, characterised by age-inappropriate levels of behavioural impulsivity, hyperactivity and inattention (American Psychiatric Association, 1994). The disorder is relatively common, with estimates ranging around $3-5 \%$ of school age children (Buitelaar, 2002), persisting into adulthood in about 30-50\% of cases (Weiss \& Hechtman, 1993).

\section{Executive function deficits}

Individuals with ADHD typically show impairments of executive function, particularly in the domains of working memory (including spatial and verbal working memory), sustained attention and response inhibition, although the extent of these deficits varies from child to child (Nigg, 2005). Two reviews (Nigg, 2005; Willcutt et al., 2005) found that case/control differences for these functions were associated with Cohen's d effect sizes between .46 and .75 , suggesting that these executive functions discriminate reasonably well between individuals with and without ADHD.

\section{Genetic evidence}

ADHD has a strong genetic component, with additive effects of multiple genes explaining around $80 \%$ of an individual's susceptibility to ADHD (Thapar et al., 1999). Studies looking at ADHD prevalence show siblings of an individual with ADHD to be three to five times more likely to be affected with ADHD than the general population (Faraone et al., 1993), while monozygotic twins have a concordance of $50-80 \%$ compared with 33\% for dizygotic twins (Bradley \& Golden, 2001). Studies investigating the influence of candidate genes have mostly focused on the catecholamine system (specifically dopamine and noradrenaline), as well as genes associated with the indolamine serotonin (see Voeller, 2004 for an overview).

\section{Autism Spectrum Disorders}

Symptoms 
Autism, high-functioning autism and Asperger's syndrome, grouped under the term autism spectrum disorders (ASDs), are neurodevelopmental disorders clinically defined by deficits in social behaviour, delayed onset of verbal and non-verbal communication and unusual patterns of restricted, repetitive behaviours and interest, before the age of three years (American Psychiatric Association, 1994).

\section{Executive function deficits}

Abnormalities in executive function in the ASDs include deficits in working memory (Silk et al., 2006), planning (Ozonoff \& Jensen, 1999), set shifting (Verte et al., 2005), response inhibition (Johnson, Robertson et al., 2007), and different aspects of attention, including orienting (Townsend et al., 1996) and shifting (Rinehart et al., 2006).

\section{Genetic evidence}

The ASDs have a strong genetic component to their aetiology (Bailey et al., 1995) with heritability estimates of up to $90 \%$ (Ronald et al., 2006). Each of the three core behaviours of the ASDs may have independent genetic origins (Ronald et al., 2006). The genetic origins of the ASDs are complex; no one gene has been unequivocally identified as containing risk alleles for autism. In a recent review of the genome-wide linkage studies for autism and the ASDs, 94 loci were reported as potential candidate genes (Yang \& Gill, 2007).

\section{Endophenotypes}

ADHD, the ASDs and Schizophrenia are representative of many complex psychiatric disorders, in that symptoms and aetiologies may vary widely among patients. This renders the detection of candidate genes highly problematic. A hypothesised solution to this problem is the application of endophenotypes, which are measurable quantitative 
traits that lie intermediate between gene function and behaviour, and can be more clearly linked to genetic variation (Gottesman \& Gould, 2003).

Neuroimaging technologies such as functional magnetic resonance imaging (fMRI) provide a sensitive measure of the efficiency of cognitive networks and may be a more suitable assay of underlying genetic influences than purely behavioural measures. The utility of fMRI may be particularly apparent in conditions where individual differences in behavioural measures are minimal due to either ceiling or floor effects on the neurocognitive task under study. Neuroimaging of cortical activity during performance of behavioural tests of sustained attention, response inhibition and working memory may therefore provide more sensitive endophenotypes for disorders of the executive system than behavioural testing alone.

\section{Functions}

\section{Sustained attention:}

Sustained attention refers to the ability to maintain focus on a task without exogenous alerting (Robertson et al., 1997). Heritability estimates for sustained attention vary considerably depending on the measure employed, ranging from around $20 \%$ to $70 \%$ (Boomsma, 1998; Heiser et al., 2006).

A catecholamine (dopamine and noradrenaline) model of attention has been proposed which relies heavily on the activity of the right frontal and parietal cortices (Levy \& Swanson, 2001; Posner \& Peterson, 1990). Performance of sustained attention tasks has been consistently shown to activate a fronto-parietal cortical network, largely lateralised to the right hemisphere (Lawrence et al., 2003), although left prefrontal cortex (Fassbender et al., 2004) and subcortical regions including the thalamus and putamen (Kinomura et al., 1996; Paus et al., 1997) have also been implicated. 


\section{Sustained Attention in Normal Populations}

Researchers have investigated the role of several dopaminergic genes in the modulation of attention. The COMT gene codes for the catechol-O-methyltransferase enzyme, responsible for the degradation of dopamine. The Met allele of a polymorphism at position 158 within this gene breaks down dopamine more slowly and results in higher levels of cortical dopamine (Lachman et al., 1996) than the Val allele. While Blasi et al. (2005) found an association between COMT and attentional control, others (Fossella et al., 2002; Stefanis et al., 2004) found no association between COMT genotype and sustained attention in normal populations.

Two fMRI studies of attentional control (Blasi et al., 2005; Heinz \& Smolka, 2006) found lower activity levels in the anterior cingulate with increasing dose of the COMT Met allele. Combined with findings that the Met allele is associated with better performance of this task, this indicates that the Met allele produces a more focused response, and contributes towards a more efficient prefrontal attention network than the Val allele (also see Winterer et al., 2006). In contrast with this interpretation, Fan et al. (2003) found that increased efficiency of the conflict network in the Attention Network Test (ANT) was associated with augmented activity in the anterior cingulate. In a study of the effects of the dopaminergic genes MAOA and DRD4 (coding for the dopamine D4 receptor) on attention networks, the authors found that the alleles of the two genes that were known to be associated with better performance on the task were associated with increased, not decreased cortical activity. Some association of a polymorphism in Exon III of DRD4 with attention problems in normally-developing children had previously been demonstrated (Auerbach et al., 2001; Schmidt et al., 2001), however no association was found between any variant of the DRD4 gene and the efficiency of the ANT alerting network (Fossella et al., 2002). The alerting network is assayed by comparing response times under a condition in which participants must maintain response readiness in the absence of an alerting cue, compared to response times when this alerting cue is provided. Thus, the alerting network may be considered somewhat analogous to the 
sustained attention network described above, as in both cases attention must be maintained without exogenous alerting.

Fossella and colleagues did however find the efficiency of the alerting network to be modulated by a $30 \mathrm{bp}$ promoter region polymorphism in the MAOA gene, responsible for the degradation of serotonin and noradrenaline. The neurotransmitter serotonin and its associated genes have traditionally been considered to play a role in affective and emotional regulation (see other articles within this special edition). In a different context, however, polymorphisms in the gene coding for the serotonin transporter (5HTT) have also been linked with differences in activation of the anterior cingulate during a Strooptype task (Canli et al., 2005).

\section{Sustained Attention in Schizophrenia}

Difficulties with sustained attention are a well known symptom of schizophrenia (Egeland et al., 2003). Although patients with schizophrenia show significant deficits on tests of sustained attention relative to their unaffected relatives, the family members perform less well than control subjects (e.g. Cornblatt et al., 1999), indicating a familial risk profile for sustained attention deficits in schizophrenia. Patients with schizophrenia have been reported to display lower levels of activation in anterior and posterior cingulate, right lateral frontal cortex and superior temporal gyrus during performance of tasks requiring sustained attention (Carter et al., 1997; Kiehl \& Liddle, 2001).

The nicotine system has been implicated in the modulation of attention in schizophrenia (Harris et al., 2004), and one study reported an association between a polymorphism in Exon 5 of the CHRNA4 gene, coding for the nicotinic acetylcholine a 4 subunit, and performance on an auditory oddball task measuring sustained attention (Winterer et al., 2007). Variation at the CHRNA4 locus was also associated with the efficiency of attention networks in the anterior cingulate and parietal cortex.

Sustained attention difficulties in schizophrenia have also been related to variation in several other genes, including the serotonin 2A receptor gene (Ucok et al., 2007), DISC1 
(Liu et al., 2006) and dysbindin (Donohoe et al., 2007), but not to COMT genotype (Smyrnis et al., 2007).

\section{Sustained attention in ADHD}

Inferior target detection on tasks of sustained attention is reliably reported in children with ADHD compared to matched controls (e.g. Johnson, Kelly et al., 2007a), although it has been suggested that the absence of robust time-on-task effects in ADHD argues against significant impairment in sustained attention (Stins et al., 2005). More recent work within the cognitive neurosciences, however, shows that brief lapses of sustained attention, as measured by poor target detection, are preceded by momentary reductions of activity in frontal control regions (Weissman et al., 2006). Sustained attention deficits in ADHD may thus be influenced by both a failure in the moment-to-moment control of attention as well as a more gradual diminution in arousal over time (Johnson, Kelly et al., 2007a).

While we have found no studies relating specific candidate genes to functional brain differences in children with ADHD during sustained attention performance, a number of genes thought to modulate sustained attention in the disorder have been identified. A number of polymorphisms in the gene encoding the dopamine transporter (DAT1) have been tested for association with ADHD. A VNTR in the 3' untranslated region of the gene has been associated with a diagnosis of ADHD in many (e.g. Barkley et al., 2006; Barr et al., 2001; Gill et al., 1997) but not all (e.g. Todd et al., 2001) populations. An association between the 10-repeat allele of this marker and sustained attention deficits has been reported in ADHD (Bellgrove, Hawi, Kirley et al., 2005).

In addition to this finding, the 7-repeat allele of the DRD4 gene has been associated with increased errors of commission in individuals with ADHD, when performing sustained attention tasks (Kieling et al., 2006), but see Bellgrove, Hawi, Lowe et al (2005) for a contrasting result. In children with ADHD, performance on sustained attention tasks has also been linked to variation in the DBH gene (Bellgrove, Mattingley et al., 2006). DBH codes for the dopamine $\beta$-hydroxylase enzyme which catalyses the conversion of 
dopamine to noradrenaline. ADHD children with two copies of an allele that was previously associated with ADHD (A2 allele of an Intron 5 polymorphism) performed more poorly on a test of sustained attention than ADHD children possessing fewer copies of this allele (Bellgrove, Hawi et al., 2006). The Val variant of the COMT gene has been associated with better performance on a sustained attention task, in children with ADHD (Bellgrove, Domschke et al., 2005), contrary to what is typically found in the general population.

\section{Sustained Attention in ASDs}

Only a handful of studies have investigated sustained attention in children with ASD and most studies have reported intact sustained attention (for a review see Johnson, Robertson et al., 2007). To date, there have been no functional neuroimaging studies of sustained attention in autism spectrum disorders, however given the neuroanatomical debate as to whether the parietal cortex is implicated in autism (for a review see Schmitz et al., 2007), it would be valuable to examine the function of the frontal and parietal cortices during a sustained attention task in people with ASD (Sanders et al., 2007). It may be the case that, as was found in other tests of executive function (Schmitz et al., 2006), normal performance is achieved by a number of compensatory mechanisms which might be observed with fMRI.

We are not aware of any studies that have examined the impact of any candidate genes on brain function during sustained attention in ASD.

\section{Working Memory:}

The classical view of working memory (see Baddeley, 1992) maintains that it is a system for the short-term storage of information, composed of a central executive and two 'slave' systems, a phonological loop and a visuospatial sketchpad, which temporarily store auditory and visual information, respectively. This view accords with the common division of working memory processes into those dealing with storage or maintenance of information, and those dealing with manipulation of that same information. Working 
memory appears to have a significant genetic component, with estimates of its heritability ranging from 33\% to 49\% (Ando et al., 2001; Wright et al., 2001).

The process of working memory is largely subserved by the prefrontal cortex (although the role of the dorsolateral prefrontal cortex (DLPFC) remains controversial; McCarthy et al., 1994; Petrides, 1994) in conjunction with regions of the parietal cortex, and is known to be mediated by dopaminergic systems (Mehta et al., 2001; Muller et al., 1998). Dopamine is believed to have an inverted U-shaped dose/response curve for working memory whereby either too much or too little dopamine will result in sub-optimal performance (Vijayraghavan et al., 2007). Noradrenaline has also been shown to be a key neurotransmitter for working memory (see Chamberlain et al., 2006 for a review). Similarly to dopamine, an optimal level of noradrenaline appears critical for working memory.

\section{Working Memory in Normal Populations}

A number of studies have examined the impact of COMT genotype on working memory in healthy controls. While several studies found no significant differences in working memory performance among genotype groups (e.g. Bertolino, Blasi et al., 2006; Bruder et al., 2005; Stefanis et al., 2004), those studies that did find differences converge to suggest that the less active Met allele is associated with better verbal or numerical working memory performance (e.g. Diamond et al., 2004; Goldberg et al., 2003).

The relevance of the COMT Val/Met polymorphism to working memory was demonstrated in an fMRI study. Amphetamine, which binds to the dopamine transporter and reduces reuptake of extrasynaptic dopamine, was administered to participants with differing COMT genotypes prior to performance of a working memory task. Amphetamine resulted in improvement in cortical efficiency and reaction time for Val/Val participants, while it reduced cortical efficiency and impaired performance in the most difficult task condition for Met/Met participants (Mattay et al., 2003). The implication of this is that efficient performance of prefrontal-dependent tasks relies on the presence of an optimal level of extrasynaptic dopamine. The increase in dopamine 
occasioned by the administration of amphetamine will therefore have differential effects on performance depending on the baseline dopamine levels produced by COMT genotype.

Two studies of the effects of this polymorphism on brain activation during performance of a non-spatial working memory n-back task found the Met allele to be associated with a more focused, efficient cortical response than the Val allele (Bertolino, Blasi et al., 2006; Egan, Goldberg, Kolachana et al., 2001). Bertolino and colleagues also assessed the impact of the 3' VNTR in the DAT1 gene on cortical activation during this task; not only was the 10-repeat allele associated with a more efficient cortical network, but homozygosity for both the DAT1 10-repeat allele and the COMT Met allele was linked with the most focused response of all, indicating an additive effect of these genes on the working memory cortical network. Similarly, Caldú et al. (2007) found homozygosity for both the DAT1 9-repeat allele and COMT Val allele to be associated with the highest level of activation during an n-back task. An association was also reported between variation in the DRD2 gene and working memory ability in normal participants. This association was strengthened when interaction with the COMT Val/Met polymorphism was investigated (Xu et al., 2007).

An association of the G444A marker of the DBH gene with spatial working memory performance has been demonstrated. Increasing dosage of the high-activity $\mathrm{G}$ allele is associated with lower levels of the DBH in plasma and cerebrospinal fluid (Cubells et al., 1998), and was found to be linked to greater accuracy on the more difficult conditions of a spatial working memory storage task, but not on a visuospatial attention task (Parasuraman et al., 2005). The G444A marker has previously been shown to be in strong linkage disequilibrium with the main functional variant controlling plasma $\mathrm{D} \beta \mathrm{H}$ levels, the C-1021T polymorphism (Zabetian et al., 2003), however no links with spatial working memory have been demonstrated for this marker. The authors found no association of a polymorphism in the CHRNA4 gene, reported to be linked with visuospatial attention, with spatial working memory in this study. Research performed in other groups has indicated no association between working memory performance and 
variation in the DAT1 (Bertolino, Blasi et al., 2006), 5HTT (Hariri et al., 2002), NET (Szöke et al., 2006) or MAOA (Yu et al., 2005) genes.

\section{Working Memory in Schizophrenia}

Working memory deficits are a core neuropsychological symptom of schizophrenia (Goldman-Rakic, 1991). The extent of these deficits is thought to be mediated by a number of genes, including COMT (Egan, Goldberg, Kolachana et al., 2001), Reelin (Wedenoja et al., 2007), Neureglin (Stefanis et al., 2007), DISC1 (Burdick et al., 2005), DAT1 (Rybakowski et al., 2006) and several of the dopamine receptor genes (Rybakowski et al., 2005; Szekeres et al., 2004).

Abnormalities in prefrontal function during performance of working memory tasks are frequently reported in schizophrenia. Many of these studies indicate hypoactivation of lateral prefrontal cortex (e.g. Barch \& Csernansky, 2007), while others describe either increased activation in those areas (Callicott et al., 2000; Manoach et al., 1999), or no apparent difference from control participants (Walter et al., 2007). This has led to the suggestion that changes in cortical activation with increasing task demands or memory load may also follow an inverted-U shaped curve. This appears to be the case even after controlling for the effect of COMT genotype (Bertolino, Caforio et al., 2006). Abnormalities in parietal activation are also common; schizophrenic patients appear to demonstrate decreased activation in dorsal and ventral inferior parietal cortex (Barch \& Csernansky, 2007; Schneider et al., 2007), however some contradictory results have also been reported (Mendrek et al., 2005; Thermenos et al., 2005).

A genetic link to the functional abnormalities observed in the brains of schizophrenic patients is supported by the discovery that the unaffected first degree relatives of patients display significantly greater DLPFC activation than controls during working memory tasks (e.g. Callicott et al., 2003). The majority of genetic neuroimaging studies of working memory in schizophrenia address the impact of COMT genotype on cortical response. The consensus of these studies is that increasing gene dosage of the Met allele is associated with a more efficient prefrontal cortical response during performance of 
working memory tasks (Bertolino, Caforio et al., 2006; Egan, Goldberg, Kolachana et al., 2001; Ho et al., 2005). Further, improvement in both behavioural working memory performance and prefrontal efficiency following a course of the antipsychotic medication olanzapine is predicted by Met allele load (Bertolino et al., 2004).

Cortical activity relating to working memory may be affected in schizophrenia by genes involved in other neurochemical systems; for example, a schizophrenia-associated polymorphism in the DISC1 gene has been shown to have an effect on hippocampal activation during working memory (Callicott et al., 2005).

\section{Working Memory in ADHD}

A number of studies suggest that individuals with ADHD demonstrate problems with working memory. For example, medication-naïve children with ADHD were found to be impaired in spatial-working memory, compared with control children or children with ADHD on stimulant medication (Barnett et al., 2001). Impairments in working memory in individuals with ADHD are associated with low levels of striatal dopamine (e.g. Frank et al., 2007), and often respond well to stimulant medications that increase dopaminergic activity (for a review see Pietrzak et al., 2006).

A growing number of studies have used functional imaging to investigate ADHD (see Fassbender \& Schweitzer, 2006 for an overview). Based on the current evidence, they suggest that in individuals with ADHD the processing of executive functions such as sustained attention, response inhibition and working memory is often taken over by other (presumably unaffected) regions, while hypoactivity is observed in those (affected) regions that are typically engaged in processing the task. Individuals with ADHD show reduced activation in prefrontal areas (as well as other regions including cerebellum and occipital cortex) when engaged in a verbal working memory task (Valera et al., 2005). Relatively few studies have imaged spatial working memory in ADHD, despite the robust effect sizes associated with behavioural measures of spatial working memory (see Martinussen et al., 2005, pp. for a meta-analysis). Reductions in activity within the right parietal lobe, as well as occipital areas including the cuneus and precuneus, have been 
observed during mental rotation, a process requiring the spatial storage of relations between objects (Silk et al., 2005; Vance et al., 2007).

Very few studies of genetic effects on working memory in ADHD have been published. A recent article by Levy (2007) reviewed the relationship between COMT polymorphisms and response to treatment medication in individuals with ADHD. Individuals possessing the more active Val variant typically perform better with stimulant medication on tests that assess working memory, unlike individuals homozygous for the Met variant whose performance decreases. A study by Dorval and colleagues (2007) found the GRIN2B gene to be associated with ADHD symptoms such as inattentiveness and hyperactivity, but not with either verbal working memory or short term memory (also see Adams et al., 2004 for similar negative findings regarding the link between GRIN2A and working memory).

\section{Working Memory in ASDs}

People with ASD frequently demonstrate deficits in working memory (for a review see Russo et al., 2007). A number of functional imaging studies have been conducted examining differences in cortical activation in participants with ASD during performance of working memory tasks. A study by Koshino and colleagues (2005) using an N-back working memory task with letter stimuli found that, despite the absence of any differences in performance, adults with ASD showed less activation in the left prefrontal regions than controls, especially in DLPFC, inferior frontal gyrus and posterior precentral sulcus. The authors suggest that as verbal working memory is related to the left prefrontal cortex, and non-verbal working memory to the right, the adults with ASD may have been processing the letter stimuli as visual codes rather than verbal information. These participants also showed increased activation of the right parietal cortex and decreased activation of the left, again suggesting that the letter stimuli were processed as non-verbal, visual graphics rather than using a phonological code. A later study by the same group (Koshino et al., 2007) found less activation in left prefrontal and right posterior temporal cortices during an N-back working memory task using facial stimuli. The implication here is that participants with ASD process faces purely as objects, 
without the emotional element. Functional connectivity analyses suggested lower connectivity with the frontal areas but normal connectivity with the parietal cortices, indicating a fundamentally different cortical network for working memory processing in autism. This makes any extrapolation of findings to a normal population highly problematic.

Similar differences in cortical activation were observed in the performance of several other working memory tasks; on a mental rotation task, adolescents with ASD demonstrated less activation in the DLPFC, anterior cingulate, the lateral and medial premotor area and the caudate nucleus, but normal activation in the parietal cortices (Silk et al., 2006), while on a spatial working memory task, adults with ASD showed less activation of the DLPFC and posterior cingulate cortex than controls (Luna et al., 2002). Normal activation was shown in the anterior cingulate cortex, insula, basal ganglia, thalamus and lateral cerebellum.

Although we are aware of no studies examining the effects of specific candidate genes in working memory in ASDs, it appears that spatial working memory deficits, as measured by the delayed oculomotor response task, may have a genetic component. Parents of children with ASD demonstrated poorer spatial accuracy than a control group, but normal levels of premature saccades (eye movements towards a stimulus) and normal latency of remembered saccades, suggesting the parents of ASD probands exhibited spatial working memory deficits (Koczat et al., 2002). We are aware of no functional imaging studies, however, addressing genetic links to working memory deficits in ASD.

\section{Response Inhibition:}

Response inhibition, the ability to withhold a prepotent response to a stimulus, is considered to be a critical measure of executive function (Chambers et al., 2006; Dempster \& Brainerd, 1995), and is often assessed by the use of Go/No-Go or Stop Signal tasks. Studies with the unaffected family members of clinical groups with response inhibition deficits have indicated that the ability to inhibit a response includes a 
heritable component (e.g. Slaats-Willemse et al., 2003). The extent of that heritability is however unclear, varying from 0 to 54\% (Groot et al., 2004; Heiser et al., 2006).

In a similar fashion to sustained attention, correct inhibition of a prepotent response recruits a distributed cortical network largely lateralised to the right hemisphere (Garavan et al., 1999), with heavy reliance on both parietal and ventral prefrontal cortices (Aron et al., 2003; Chambers et al., 2006; Menon et al., 2001). The role of dopamine in response inhibition has been described in a number of studies (e.g. Mink, 2001; Roesch-Ely et al., 2005). For example, one study administered the dopamine precursor levodopa to participants during performance of a Go/No-Go task (Hershey et al., 2004). The resulting increase in cortical dopamine levels led to lower activation in right parietal and cerebellar regions in the absence of any difference in performance accuracy or reaction time. This implies more efficient response inhibition processing with increased dopamine levels.

\section{Response Inhibition in Normal Populations}

A number of genes of the dopaminergic system have been implicated in the process of response inhibition, although few studies have addressed this relationship in normal populations. In one study however, normal children homozygous for the 10 repeat allele of DAT1 were found to perform less well on a test of response inhibition than children with one copy of the allele (Cornish et al., 2005), further highlighting the contribution of that allele to executive function. A more recent study has reported an interaction between polymorphisms of the DRD4 and DAT1 genes on response inhibition. Carriers of the 7repeat DRD4 allele who were also homozygous for the 10-repeat DAT1 allele displayed poorer response inhibition on a stop-signal task (Congdon et al, 2007).

A body of evidence has indicated a role for the serotonin system in impulse control and response inhibition (Lucki, 1998). A logical progression of this was that a polymorphism in the serotonin transporter gene (5HTT), which leads to reduced gene transcription and diminished serotonin uptake (Lesch et al., 1996), might be involved in these processes. Nevertheless, a number of studies (Clark et al., 2005; Fallgatter et al., 1999) failed to 
demonstrate an association between the 5HTTLPR polymorphism and performance on either a CPT or stop signal reaction time task.

The TPH2 gene exercises control over tryptophan hydroxylase, a rate-limiting enzyme in the catalysis of serotonin from tryptophan (Grahame-Smith, 1964). Variation in this gene has been associated with increased error rates on the ANT conflict network measure, indicating decreased impulse control (Reuter et al., 2007), and with reaction times in a Stop Task (Stoltenberg et al., 2006), although this trend was only significant for male participants. Variation in this gene is known to influence amygdala reactivity, but we are not aware of any neuroimaging studies addressing disparity in any executive functions relating to this gene.

Some evidence has been provided for association between the serotonergic MAOA gene and response inhibition in normal populations (Passamonti et al., 2006). Variation in a promoter-region polymorphism of this gene was not significantly associated with performance of a Go/No-Go task (although carriers of the high-activity allele tended to make more errors of commission), but differences in cortical activation during performance of the task were observed. Carriers of the less active allele, which would be expected to degrade noradrenaline and serotonin more slowly, displayed higher levels of cortical activity in bilateral extrastriate cortex and right superior parietal cortex, but lower activation levels in right ventrolateral prefrontal cortex than carriers of the high-activity allele.

\section{Response Inhibition in Schizophrenia}

Difficulty with response inhibition is representative of the general neuropsychological deficits seen in schizophrenia (Wykes et al., 2000), and patients have been shown to demonstrate poor performance in response inhibition tasks relative to healthy controls (Thoma et al., 2007). One of the most frequently reported neurocognitive markers of schizophrenia is difficulty with performance of antisaccades, that is, voluntary inhibition of automated ocular saccades towards a light stimulus (Crawford et al., 1995; Fukushima 
et al., 1988). Antisaccade performance has been closely linked with capacity for response inhibition (Donohoe et al., 2006).

A commonly reported neurological sign of schizophrenia is frontal hypoactivity during performance of executive function tasks (Chua \& McKenna, 1995), and patients have been shown to demonstrate reduced activity in the left anterior cingulate and DLPFC during response inhibition tasks (Rubia et al., 2001). Schizophrenic patients and their healthy siblings both fail to show normal increases in striatal activation during preparation for response inhibition (Vink et al., 2006).

Response inhibition in schizophrenia may be influenced by COMT genotype; one study found that participants homozygous for the Met allele outperformed those in possession of one or two copies of the Val allele on a Stroop test (Ehlis et al., 2007). We are aware of no other studies addressing the effect of specific genes on response inhibition in schizophrenia, or on associated cortical activity.

\section{Response Inhibition in ADHD}

A recent review article by Wodka and colleagues (2007) suggests that response inhibition should be seen as one of the key deficits in ADHD, even when cognitive task demands are minimal (but see also Rommelse et al., 2007). Deficiencies in response inhibition have been proposed as a valuable cognitive endophenotype for ADHD (Aron \& Poldrack, 2005).

In a study with normal participants (Bellgrove et al., 2004), behavioural differences such as increased response variability and an increase in commission errors (both of which have been observed in ADHD, see Johnson, Kelly et al., 2007b; Wodka et al., 2007), were shown to dissociate the brain regions used in a Go/No-Go task. Efficient response inhibition was associated with activity in regions including the middle frontal and inferior frontal gyri. These regions are often found to be affected in ADHD, being smaller in size and often displaying hypofunction (Durston et al., 2004), suggesting that the poor 
performance of people with ADHD on these tasks may be exacerbated by relying on compromised brain regions.

The 7-repeat allele of a VNTR in the DRD4 gene has been associated with an impulsive and inaccurate response style in children with ADHD, independent of symptom severity (Langley et al., 2004). The 10-repeat polymorphism of the DAT1 gene has also been implicated in deficiencies in response inhibition in a population-based sample of boys who scored high on a measure of ADHD symptoms (Cornish et al., 2005). This strongly implies a role for the DRD4 and DAT1 genes in particular, and the dopamine system in general, in the process of response inhibition.

Although response inhibition deficits have been observed in ADHD, and have been linked with a number of genetic markers, no studies to date have examined genetic effects on abnormalities in cortical activation observed during response inhibition in children with ADHD.

\section{Response Inhibition in ASDs}

The issue of whether or not children with ASDS display deficits on response inhibition tasks is contentious (Sanders et al., 2007). Studies have demonstrated normal response inhibition abilities on tasks such as the Stroop test (Goldberg et al., 2005; Ozonoff \& Jensen, 1999), the stop signal paradigm (Ozonoff \& Strayer, 1997), and inhibition in the neutral condition of a Go/No-Go task (Ozonoff \& McEvoy, 1994). Other studies have shown deficits on the prepotent inhibition of a Go/No-Go task (Ozonoff \& McEvoy, 1994), the Windows task (Ozonoff \& McEvoy, 1994), the random Sustained Attention to Response Task (SART; Johnson, Robertson et al., 2007), oculomotor anti-saccade task (Luna et al., 2007) and the Detour Reaching task (Hughes \& Russell, 1993).

Despite normal behavioural performance on a Go/No-Go task, functional imaging showed increased activation of the frontal and parietal cortices in a group of adults with ASD, compared with controls (Schmitz et al., 2006). Greater left hemisphere activity in 
the inferior and orbitofrontal cortices may indicate an alternative, compensatory mechanism in these participants (Schmitz et al., 2006). In another Go/No-Go task, adults with ASD showed normal behavioural performance but reduced brain activation in the right cingulate gyrus, right insula, right inferior frontal gyrus, right premotor cortex, but normal activation in the parietal cortices (Kana et al., 2007). In a slightly more difficult condition of the task including a working memory component, participants with ASD displayed activation in the anterior cingulate and parietal cortex and increased activity in premotor regions, areas associated with processing cues in readiness to respond.

No specific candidate genes have as yet been associated with response inhibition deficits in autism.

\section{Conclusions}

Investigations into the genetic correlates of individual differences in executive control have to date produced disparate findings. Initial positive results are frequently not replicated in subsequent studies (see for example the often contradictory literature relating variation in the DRD4 gene to sustained attention in ADHD). These disparities can be partially attributed to small effect sizes of individual genes, and the fact that multiple genes may contribute to a single function. In addition, while the various executive functions may be relatively easily discriminated at the behavioural level, the distinctions between them are less clear cut at the genetic level, with similar genetic foundations appearing to support a wide variety of functions. Similarly, imaging studies reveal that the three executive functions discussed here display extensive overlap in the brain regions recruited; working memory, sustained attention, and response inhibition all activate functional networks involving prefrontal and parietal regions. To some extent this may reflect common components to these functions, allowing us to group them together under the name 'executive functions'. Careful manipulation of the task characteristics has, however, been shown to dissociate between partially overlapping and interacting functional networks in these regions (see e.g. Corbetta \& Shulman, 2002; Lungu et al., 2007; Wager \& Smith, 2003). This again underpins the importance of using 
cognitive endophenotypes which maximally dissociate the underlying function and associated brain regions.

The low power common to studies of this kind has led to the current trend for large scale consortia that can conduct genome-wide association studies of disorders or processes to give firm leads on candidate genes and to identify quantitative trait loci. This approach also has the potential to identify novel variants for which no a priori hypothesis for an association with executive control exists. To date, no genome-wide association studies of sustained attention, spatial working memory or response inhibition have been conducted. To some extent, imaging studies may be helpful in providing the power that is sought in genetic studies by acting as endophenotypes with higher signal-to-noise ratios. Cognitive neuroscience allows us to define cognitive-neuroanatomical models which can constrain linkages between a gene and a process based on what we know about where the gene is expressed and how a cognitive function is influenced by different neurotransmitters. For example, working memory is known to activate prefrontal regions, and to be heavily dependent on dopamine (Vijayraghavan et al., 2007). The discovery that the dopamine transporter is sparse in prefrontal cortex led to an appreciation of the role of catechol-Omethyltransferase as the main vehicle for dopamine clearance in the prefrontal cortex, and provided a rationale for association studies of the COMT gene with working memory performance (Sesack et al., 1998).

Furthermore, genetics may be used to test cognitive-neuroanatomical models of cognition. As yet, no studies of which we are aware have demonstrated a double dissociation between genetic links to the neurological correlates of two discrete executive functions, although studies of this nature have been conducted to discriminate genetic effects on cortical activation related to emotional processing from activation related to working memory (Hariri et al., 2002; Heinz \& Smolka, 2006). The scope for real discovery in this area is broad; it might, for example, be possible to find a dissociation between genes for spatial versus verbal working memory, or for sustained versus spatial attention. The current developments in neuroimaging and genetics are therefore 
producing what may be one of the most informative lines of research in the field of executive function. 


\section{References}

Adams, J., Crosbie, J., Wigg, K., Ickowicz, A., Pathare, T., Roberts, W., et al. (2004). Glutamate receptor, ionotropic, N-methyl D-aspartate 2A (GRIN2A) gene as a positional candidate for attention-deficit/hyperactivity disorder in the $16 \mathrm{p} 13$ region. Molecular Psychiatry, 9(5), 494-499.

American Psychiatric Association. (1994). Diagnostic and Statistical Manual of Mental Disorders IV

Washington DC: American Psychiatric Association.

Ando, J., Ono, Y., \& Wright, M. J. (2001). Genetic structure of spatial and verbal working memory. Behavioral Genetics, 31(6), 615-624.

Aron, A. R., Fletcher, P. C., Bullmore, E. T., Sahakian, B. J., \& Robbins, T. W. (2003). Stop-signal inhibition disrupted by damage to right inferior frontal gyrus in humans. Nat Neurosci, 6(2), 115-116.

Aron, R. A., \& Poldrack, R. A. (2005). The cognitive neuroscience of response inhibition: Relevance for genetic research in attention-deficit/hyperactivity disorder. Biological Psychiatry, 57, 1285-1292.

Auerbach, J. G., Benjamin, J., Faroy, M., Geller, V., \& Ebstein, R. (2001). DRD4 related to infant attention and information processing: a developmental link to ADHD? Psychiatric Genetics, 11(1), 31-35.

Badcock, J. C., Michie, P. T., Johnson, L., \& Combrinck, J. (2002). Acts of control in schizophrenia: dissociating the components of inhibition. Psychological Medicine, 32(2), 287-297.

Baddeley, A. (1992). Working Memory. Science, 255, 556-559.

Bailey, A., Lecoutteur, A., Gottesman, I., Bolton, P., Simonoff, E., Yuzda, E., et al. (1995). Autism as a strongly genetic disorder - evidence from a British twin study. Psychological Medicine, 25(1), 63-77.

Barch, D. M., \& Csernansky, J. G. (2007). Abnormal Parietal Cortex Activation During Working Memory in Schizophrenia: Verbal Phonological Coding Disturbances Versus Domain-General Executive Dysfunction. American Journal of Psychiatry, 164(7), 1090-1098.

Barkley, R. A., Smith, K. M., Fischer, M., \& Navia, B. (2006). An examination of the behavioral and neuropsychological correlates of three ADHD candidate gene polymorphisms (DRD4 7+, DBH TaqI A2, and DAT1 40 bp VNTR) in hyperactive and normal children followed to adulthood. American Journal of Medical Genetics Part B: Neuropsychiatric Genetics, 141(5), 487-498.

Barnett, R., Maruff, P., Vance, A., Luk, E. S., Costin, J., Wood, C., et al. (2001). Abnormal executive function in attention deficit hyperactivity disorder: the effect of stimulant medication and age on spatial working memory. . Psychological Medicine, 31, 1107-1115.

Barr, C. L., Xu, C., Kroft, J., Feng, Y., Wigg, K., Zai, G., et al. (2001). Haplotype study of three polymorphisms at the dopamine transporter locus confirm linkage to attention defict/hyperactivity disorder. Biological Psychiatry., 49, 333-339.

Bellgrove, M. A., Domschke, K., Hawi, Z., Kirley, A., Mullins, C., Robertson, I. H., et al. (2005). The methionine allele of the COMT polymorphism impairs prefrontal 
cognition in children and adolescents with ADHD. Experimental Brain Research, 163(3), 352-360.

Bellgrove, M. A., Hawi, Z., Gill, M., \& Robertson, I. H. (2006). The cognitive genetics of attention deficit hyperactivity disorder (ADHD): sustained attention as a candidate phenotype. Cortex, 42(6), 838-845.

Bellgrove, M. A., Hawi, Z., Kirley, A., Gill, M., \& Robertson, I. H. (2005). Dissecting the attention deficit hyperactivity disorder (ADHD) phenotype: sustained attention, response variability and spatial attentional asymmetries in relation to dopamine transporter (DAT1) genotype. Neuropsychologia, 43(13), 1847-1857.

Bellgrove, M. A., Hawi, Z., Lowe, N., Kirley, A., Robertson, I. H., \& Gill, M. (2005). DRD4 gene variants and sustained attention in attention deficit hyperactivity disorder (ADHD): effects of associated alleles at the VNTR and -521 SNP. American Journal of Medical Genetics Part B: Neuropsychiatric Genetics, 136(1), 81-86.

Bellgrove, M. A., Hester, R., \& Garavan, H. (2004). The functional neuroanatomical correlates of response variability: evidence from a response inhibition task. Neuropsychologia, 42(14), 1910-1916.

Bellgrove, M. A., Mattingley, J. B., Hawi, Z., Mullins, C., Kirley, A., Gill, M., et al. (2006). Impaired temporal resolution of visual attention and dopamine beta hydroxylase genotype in attention-deficit/hyperactivity disorder. Biological Psychiatry, 60(10), 1039-1045.

Bertolino, A., Blasi, G., Latorre, V., Rubino, V., Rampino, A., Sinibaldi, L., et al. (2006). Additive effects of genetic variation in dopamine regulating genes on working memory cortical activity in human brain. Journal of Neuroscience, 26(15), 39183922.

Bertolino, A., Caforio, G., Blasi, G., De Candia, M., Latorre, V., Petruzzella, V., et al. (2004). Interaction of COMT (Val(108/158)Met) genotype and olanzapine treatment on prefrontal cortical function in patients with schizophrenia. American Journal of Psychiatry, 161(10), 1798-1805.

Bertolino, A., Caforio, G., Petruzzella, V., Latorre, V., Rubino, V., Dimalta, S., et al. (2006). Prefrontal dysfunction in schizophrenia controlling for COMT Val158Met genotype and working memory performance. Psychiatry Research, 147(2-3), 221226.

Blasi, G., Mattay, V. S., Bertolino, A., Elvevag, B., Callicott, J. H., Das, S., et al. (2005). Effect of catechol-O-methyltransferase val158met genotype on attentional control. Journal of Neuroscience, 25(20), 5038-5045.

Boomsma, D. I. (1998). Genetic analysis of cognitive failures (CFQ): a study of Dutch adolescent twins and their parents. European Journal of Personality, 12(5), 321330.

Bradley, J. D., \& Golden, C. J. (2001). Biological contributions to the presentation and understanding of attention-deficit/hyperactivity disorder: a review. Clinical Psychology Review, 21(6), 907-929.

Bruder, G. E., Keilp, J. G., Xu, H., Shikhman, M., Schori, E., Gorman, J. M., et al. (2005). Catechol-O-methyltransferase (COMT) genotypes and working memory: associations with differing cognitive operations. Biological Psychiatry, 58(11), 901-907. 
Buitelaar, J. K. (2002). Epidemiology: what have we learned over the last decade? In S. Sandberg (Ed.), Hyperactivity and attention-deficit disorders. . Cambridge, UK: Cambridge University Press.

Burdick, K. E., Hodgkinson, C. A., Szeszko, P. R., Lencz, T., Ekholm, J. M., Kane, J. M., et al. (2005). DISC1 and neurocognitive function in schizophrenia. Neuroreport, 16(12), 1399-1402.

Caldu, X., Vendrell, P., Bartres-Faz, D., Clemente, I., Bargallo, N., Jurado, M. A., et al. (2007). Impact of the COMT Val(108/158) Met and DAT genotypes on prefrontal function in healthy subjects. Neuroimage.

Callicott, J. H., Bertolino, A., Mattay, V. S., Langheim, F. J. P., Duyn, J., Coppola, R., et al. (2000). Physiological Dysfunction of the Dorsolateral Prefrontal Cortex in Schizophrenia Revisited. Cerebral Cortex, 10(11), 1078-1092.

Callicott, J. H., Egan, M. F., Mattay, V. S., Bertolino, A., Bone, A. D., Verchinksi, B., et al. (2003). Abnormal fMRI response of the dorsolateral prefrontal cortex in cognitively intact siblings of patients with schizophrenia. American Journal of Psychiatry, 160(4), 709-719.

Callicott, J. H., Straub, R. E., Pezawas, L., Egan, M. F., Mattay, V. S., Hariri, A. R., et al. (2005). Variation in DISC1 affects hippocampal structure and function and increases risk for schizophrenia. Proceedings of the National Academy of Science, 102(24), 8627-8632.

Canli, T., Omura, K., Haas, B. W., Fallgatter, A., Constable, R. T., \& Lesch, K. P. (2005). Beyond affect: a role for genetic variation of the serotonin transporter in neural activation during a cognitive attention task. Proceedings of the National Academy of Science, 102(34), 12224-12229.

Capuano, B., Crosby, I. T., \& Lloyd, E. J. (2002). Schizophrenia: genesis, receptorology and current therapeutics. Current Medicinal Chemistry, 9(5), 521-548.

Carter, C. S., Mintun, M., Nichols, T., \& Cohen, J. D. (1997). Anterior Cingulate Gyrus Dysfunction and Selective Attention Deficits in Schizophrenia: [15O]H2O PET Study During Single-Trial Stroop Task Performance. American Journal of Psychiatry, 154(12), 1670-1675.

Chamberlain, S. R., Muller, U., Blackwell, A. D., Robbins, T. W., \& Sahakian, B. J. (2006). Noradrenergic modulation of working memory and emotional memory in humans. Psychopharmacology (Berl), 188(4), 397-407.

Chambers, C. D., Bellgrove, M. A., Stokes, M. G., Henderson, T. R., Garavan, H., Robertson, I. H., et al. (2006). Executive "brake failure" following deactivation of human frontal lobe. J Cogn Neurosci, 18(3), 444-455.

Chua, S. E., \& McKenna, P. J. (1995). Schizophrenia--a brain disease? A critical review of structural and functional cerebral abnormality in the disorder. British Journal of Psychiatry, 166(5), 563-582.

Clark, L., Roiser, J. P., Cools, R., Rubinsztein, D. C., Sahakian, B. J., \& Robbins, T. W. (2005). Stop signal response inhibition is not modulated by tryptophan depletion or the serotonin transporter polymorphism in healthy volunteers: implications for the 5-HT theory of impulsivity. Psychopharmacology (Berl), 182(4), 570-578.

Corbetta, M., \& Shulman, G. L. (2002). Control of goal-directed and stimulus-driven attention in the brain. Nat Rev Neurosci, 3(3), 201-215. 
Cornblatt, B., Obuchowski, M., Roberts, S., Pollack, S., \& Erlenmeyer-Kimling, L. (1999). Cognitive and behavioral precursors of schizophrenia. Developmental Psychopathology, 11(3), 487-508.

Cornish, K. M., Manly, T., Savage, R., Swanson, J., Morisano, D., Butler, N., et al. (2005). Association of the dopamine transporter (DAT1) 10/10-repeat genotype with ADHD symptoms and response inhibition in a general population sample. Molecular Psychiatry, 10(7), 686-698.

Crawford, T. J., Haeger, B., Kennard, C., Reveley, M. A., \& Henderson, L. (1995). Saccadic abnormalities in psychotic patients. I. Neuroleptic-free psychotic patients. Psychological Medicine, 25(3), 461-471.

Cubells, J. F., van Kammen, D. P., Kelley, M. E., Anderson, G. M., O'Connor, D. T., Price, L. H., et al. (1998). Dopamine ß-hydroxylase: Two polymorphisms in linkage disequilibrium at the structural gene DBH associate with biochemical phenotypic variation. Human Genetics, 102, 533-540.

Dempster, F. N., \& Brainerd, C. J. (1995). Interference and Inhibition in Cognition. San Diego: Academic.

Diamond, A., Briand, L., Fossella, J. A., \& Gehlbach, L. (2004). Genetic and neurochemical modulation of prefrontal cognitive functions in children. American Journal of Psychiatry, 161(1), 125-132.

Donohoe, G., Morris, D. W., Clarke, S., McGhee, K. A., Schwaiger, S., Nangle, J. M., et al. (2007). Variance in neurocognitive performance is associated with dysbindin-1 in schizophrenia: a preliminary study. Neuropsychologia, 45(2), 454-458.

Donohoe, G., Reilly, R., Clarke, S., Meredith, S., Greene, B., Morris, D., et al. (2006). Do antisaccade deficits in schizophrenia provide evidence of a specific inhibitory function? Journal of the International Neuropsychological Society, 12(6), 901906.

Dorval, K. M., Wigg, K. G., Crosbie, J., Tannock, R., Kennedy, J. L., Ickowicz, A., et al. (2007). Association of the glutamate receptor subunit gene GRIN2B with attention-deficit/hyperactivity disorder. Genes, Brain and Behavior, 6(5), 444452.

Durston, S., Hulshoff Pol, H. E., Schnack, H. G., Buitelaar, J. K., Steenhuis, M. P., Minderaa, R. B., et al. (2004). Magnetic resonance imaging of boys with attention-deficit/hyperactivity disorder and their unaffected siblings. Journal of the American Academy of Child and Adolescent Psychiatry, 43(3), 332-340.

Egan, M. F., Goldberg, T. E., Gscheidle, T., Weirich, M., Rawlings, R., Hyde, T. M., et al. (2001). Relative risk for cognitive impairments in siblings of patients with schizophrenia. Biological Psychiatry, 50(2), 98-107.

Egan, M. F., Goldberg, T. E., Kolachana, B. S., Callicott, J. H., Mazzanti, C. M., Straub, R. E., et al. (2001). Effect of COMT Val 108/158 Met Genotype on Frontal Lobe Function and Risk for Schizophrenia. Proceedings of the National Academy of Science, 98, 6917-6922.

Egeland, J., Rund, B. R., Sundet, K., Landro, N. I., Asbjornsen, A., Lund, A., et al. (2003). Attention profile in schizophrenia compared with depression: differential effects of processing speed, selective attention and vigilance. Acta Psychiatria Scandinavia, 108(4), 276-284. 
Ehlis, A. C., Reif, A., Herrmann, M. J., Lesch, K. P., \& Fallgatter, A. J. (2007). Impact of catechol-O-methyltransferase on prefrontal brain functioning in schizophrenia spectrum disorders. Neuropsychopharmacology, 32(1), 162-170.

Fallgatter, A. J., Jatzke, S., Bartsch, A. J., Hamelbeck, B., \& Lesch, K. P. (1999). Serotonin transporter promoter polymorphism influences topography of inhibitory motor control. The International Journal of Neuropsychopharmacology, 2(2), 115-120.

Fan, J., Fossella, J. A., Sommer, T., Wu, Y., \& Posner, M. I. (2003). Mapping the genetic variation of executive attention onto brain activity. Proceedings of the National Academy of Science, 100(12), 7406-7411.

Faraone, S. V., Biederman, J., Lehman, B. K., Keenan, K., Norman, D., Seidman, L. J., et al. (1993). Evidence for the independent familial transmission of attention deficit hyperactivity disorder and learning disabilities: results from a family genetic study. American Journal of Psychiatry, 150(6), 891-895.

Fassbender, C., Murphy, K., Foxe, J. J., Wylie, G. R., Javitt, D. C., Robertson, I. H., et al. (2004). A topography of executive functions and their interactions revealed by functional magnetic resonance imaging. Cognitive Brain Research, 20(132-143).

Fassbender, C., \& Schweitzer, J. B. (2006). Is there evidence for neural compensation in attention deficit hyperactivity disorder? A review of the functional neuroimaging literature. Clinical Psychology Review, 26(4), 445-465.

Fossella, J. A., Sommer, T., Fan, J., Wu, Y., Swanson, J. M., Pfaff, D. W., et al. (2002). Assessing the molecular genetics of attention networks. BMC Neuroscience, 3, 14.

Frank, M. J., Santamaria, A., O'Reilly, R. C., \& Willcutt, E. (2007). Testing computational models of dopamine and noradrenaline dysfunction in attention deficit/hyperactivity disorder. . Neuropsychopharmacology, 32, 1583-1599.

Fukushima, J., Fukushima, K., Chiba, T., Tanaka, S., Yamashita, I., \& Kato, M. (1988). Disturbances of voluntary control of saccadic eye movements in schizophrenic patients. Biological Psychiatry, 23(7), 670-677.

Garavan, H., Ross, T. J., \& Stein, E. A. (1999). Right hemispheric dominance of inhibitory control: an event-related functional MRI study. Proceedings of the National Academy of Science, 96(14), 8301-8306.

Gill, M., Daly, G., Heron, S., Hawi, Z., \& Fitzgerald, M. (1997). Confirmation of association between attention deficit hyperactivity disorder and a dopamine transporter polymorphism. Molecular Psychiatry, 2, 311-313.

Goldberg, M. C., Mostofsky, S. H., Cutting, L. E., Mahone, E. M., Astor, B. C., Denckla, M. B., et al. (2005). Subtle executive impairment in children with Autism and children with ADHD. Journal of Autism \& Developmental Disorders, 35(3), 279293.

Goldberg, T. E., Egan, M. F., Gscheidle, Cappola, R., Weickert, T., Kolachana, B. S., et al. (2003). Executive subprocesses in working memory: relationship to catecholO-methyltransferase Val158Met genotype and schizophrenia. Archives of General Psychiatry, 60(889-896).

Goldberg, T. E., \& Weinberger, D. R. (2004). Genes and the parsing of cognitive processes. Trends Cogn Sci, 8(7), 325-335. 
Goldman-Rakic, P. S. (1991). Prefrontal cortical dysfunction in schizophrenia: The relevance of working memory. In B. Carroll (Ed.), Psychopathology and the Brain (pp. 1-23). New York: Raven Press.

Gottesman, I. I., \& Gould, T. D. (2003). The Endophenotype Concept in Psychiatry: Etymology and Strategic Intentions. American Journal of Psychiatry, 160(4), 636645.

Grahame-Smith, D. G. (1964). Tryptophan hydroxylation in brain. Biochemical and Biophysical Research Communications, 16(6), 586-592.

Groot, A. S., de Sonneville, L. M., Stins, J. F., \& Boomsma, D. I. (2004). Familial influences on sustained attention and inhibition in preschoolers. Journal of Child Psychology and Psychiatry, 45(2), 306-314.

Hariri, A. R., Mattay, V. S., Tessitore, A., Kolachana, B., Fera, F., Goldman, D., et al. (2002). Serotonin transporter genetic variation and the response of the human amygdala. Science, 297(5580), 400-403.

Harris, J. G., Kongs, S., Allensworth, D., Martin, L., Tregellas, J., Sullivan, B., et al. (2004). Effects of nicotine on cognitive deficits in schizophrenia. Neuropsychopharmacology, 29(7), 1378-1385.

Heaton, R. K., Gladsjo, J. A., Palmer, B. W., Kuck, J., Marcotte, T. D., \& Jeste, D. V. (2001). Stability and Course of Neuropsychological Deficits in Schizophrenia. Archives of General Psychiatry, 58(1), 24-32.

Heinrichs, R. W., \& Zakzanis, K. K. (1998). Neurocognitive deficit in schizophrenia: a quantitative review of the evidence. Neuropsychology, 12(3), 426-445.

Heinz, A., \& Smolka, M. N. (2006). The effects of catechol O-methyltransferase genotype on brain activation elicited by affective stimuli and cognitive tasks. Reviews in the Neurosciences, 17(3), 359-367.

Heiser, P., Heinzel-Gutenbrunner, M., Frey, J., Smidt, J., Grabarkiewicz, J., Friedel, S., et al. (2006). Twin study on heritability of activity, attention, and impulsivity as assessed by objective measures. Journal of Attention Disorders, 9(4), 575-581.

Hershey, T., Black, K. J., Hartlein, J., Braver, T. S., Barch, D. M., Carl, J. L., et al. (2004). Dopaminergic modulation of response inhibition: an fMRI study. Brain Research. Cognitive Brain Research, 20(3), 438-448.

Ho, B. C., Wassink, T. H., O'Leary, D. S., Sheffield, V. C., \& Andreasen, N. C. (2005). Catechol-O-methyl transferase Val158Met gene polymorphism in schizophrenia: working memory, frontal lobe MRI morphology and frontal cerebral blood flow. Molecular Psychiatry, 10(3), 229, 287-298.

Hughes, C., \& Russell, J. (1993). Autistic children's difficulty with mental disengagement from an object: it's implications for theories of autism. Developmental Psychology, 29, 298-510.

Johnson, K. A., Kelly, S. P., Bellgrove, M. A., Barry, E., Cox, M., Gill, M., et al. (2007a). Response variability in attention deficit hyperactivity disorder: evidence for neuropsychological heterogeneity. Neuropsychologia, 45(4), 630-638.

Johnson, K. A., Kelly, S. P., Bellgrove, M. A., Barry, E., Cox, M., Gill, M., et al. (2007b). Response variability in attention deficit hyperactivity disorder: evidence for neuropsychological heterogeneity. . Neuropsychologia, 45, 630-638. 
Johnson, K. A., Robertson, I. H., Kelly, S. P., Silk, T. J., Barry, E., Dáibhis, A., et al. (2007). Dissociation in performance of children with ADHD and high-functioning autism on a task of sustained attention. Neuropsychologia, 45(10), 2234-2245.

Kana, R. K., Keller, T. A., Minshew, N. J., \& Just, M. A. (2007). Inhibitory control in high-functioning autism: decreased activation and underconnectivity in inhibition networks. Biological Psychiatry, 62(3), 198-206.

Kiehl, K. A., \& Liddle, P. F. (2001). An event-related functional magnetic resonance imaging study of an auditory oddball task in schizophrenia. Schizophrenia Research, 48(2-3), 159-171.

Kieling, C., Roman, T., Doyle, A. E., Hutz, M. H., \& Rohde, L. A. (2006). Association between DRD4 gene and performance of children with ADHD in a test of sustained attention. Biological Psychiatry, 60(10), 1163-1165.

Kinomura, S., Larsson, J., Gulyas, B., \& Roland, P. E. (1996). Activation by attention of the human reticular formation and thalamic intralaminar nuclei. Science, 271(5248), 512-515.

Koczat, D. L., Rogers, S. J., Pennington, B. F., \& Ross, R. G. (2002). Eye movement abnormality suggestive of a spatial working memory deficit is present in parents of autistic probands. J Autism Dev Disord, 32(6), 513-518.

Koshino, H., Carpenter, P. A., Minshew, N. J., Cherkassky, V. L., Keller, T. A., \& Just, M. A. (2005). Functional connectivity in an fMRI working memory task in highfunctioning autism. NeuroImage, 24, 810-821.

Koshino, H., Kana, R. K., Keller, T. A., Cherkassky, V. L., Minshew, N. J., \& Just, M. A. (2007). fMRI Investigation of Working Memory for Faces in Autism: Visual Coding and Underconnectivity with Frontal Areas. Cerebral Cortex, in press.

Lachman, H. M., Papolos, D. F., Saito, T., Yu, Y. M., Szumlanski, C. L., \& Weinshilboum, R. M. (1996). Human catechol-O-methyltransferase pharmacogenetics: description of a functional polymorphism and its potential application to neuropsychiatric disorders. Pharmacogenetics, 6, 243-250.

Langley, K., Marshall, L., van den Bree, M., Thomas, H., Owen, M., O'Donovan, M., et al. (2004). Association of dopamine D4 receptor gene 7-repeat allele with neuropsychological test performance of children with ADHD. American Journal of Psychiatry, 161, 133-138.

Lawrence, N. S., Ross, T. J., Hoffmann, R., Garavan, H., \& Stein, E. A. (2003). Multiple Neuronal Networks Mediate Sustained Attention. Journal of Cognitive Neuroscience, 15(7), 1028-1038.

Lesch, K. P., Bengel, D., Heils, A., Sabol, S. Z., Greenberg, B. D., Petri, S., et al. (1996). Association of anxiety-related traits with a polymorphism in the serotonin transporter gene regulatory region. Science, 274(5292), 1527-1531.

Levy, F. (2007). What do dopamine transporter and catechol-o-methyltransferase tell us about attention deficit-hyperactivity disorder? Pharmacogenomic implications. The Australian and New Zealand Journal of Psychiatry, 41(1), 10-16.

Levy, F., \& Swanson, J. M. (2001). Timing, space and ADHD: the dopamine theory revisited. The Australian and New Zealand Journal of Psychiatry, 35(4), 504-511.

Liu, Y.-L., Fann, C. S.-J., Liu, C.-M., Chen, W. J., Wu, J.-Y., Hung, S.-I., et al. (2006). A Single Nucleotide Polymorphism Fine Mapping Study of Chromosome 1q42.1 Reveals the Vulnerability Genes for Schizophrenia, GNPAT and DISC1: 
Association with Impairment of Sustained Attention. Biological Psychiatry, 60(6), 554-562.

Lucki, I. (1998). The spectrum of behaviors influenced by serotonin. Biological Psychiatry, 44(3), 151-162.

Luna, B., Doll, S. K., Hegedus, S. J., Minshew, N. J., \& Sweeney, J. A. (2007). Maturation of executive function in autism. Biological Psychiatry, 61(4), 474481.

Luna, B., Minshew, N. J., Garver, K. E., Lazar, N. A., Thulborn, K. R., Eddy, W. F., et al. (2002). Neocortical system abnormalities in autism: an fMRI study of spatial working memory. Neurology, 59(6), 834-840.

Lungu, O. V., Liu, T., Waechter, T., Willingham, D. T., \& Ashe, J. (2007). Strategic modulation of cognitive control. J Cogn Neurosci, 19(8), 1302-1315.

Manoach, D. S., Press, D. Z., Thangaraj, V., Searl, M. M., Goff, D. C., Halpern, E., et al. (1999). Schizophrenic subjects activate dorsolateral prefrontal cortex during a working memory task, as measured by fMRI. Biological Psychiatry, 45(9), 11281137.

Martinussen, R., Hayden, J., Hogg-Johnson, S., \& Tannock, R. (2005). A meta-analysis of working memory impairments in children with attention-deficit/hyperactivity disorder. J Am Acad Child Adolesc Psychiatry, 44(4), 377-384.

Mattay, V. S., Goldberg, T. E., Fera, F., Hariri, A. R., Tessitore, A., Egan, M. F., et al. (2003). Catechol O-methyltransferase val158-met genotype and individual variation in the brain response to amphetamine. Proceedings of the National Academy of Science, 100(10), 6186-6191.

McCarthy, G., Blamire, A. M., Puce, A., Nobre, A. C., Bloch, G., Hyder, F., et al. (1994). Functional magnetic resonance imaging of human prefrontal cortex activation during a spatial working memory task. Proceedings of the National Academy of Science, 91(18), 8690-8694.

Mehta, M. A., Swainson, R., Ogilvie, A. D., Sahakian, J., \& Robbins, T. W. (2001). Improved short-term spatial memory but impaired reversal learning following the dopamine $\mathrm{D}(2)$ agonist bromocriptine in human volunteers. Psychopharmacology (Berl), 159(1), 10-20.

Mendrek, A., Kiehl, K. A., Smith, A. M., Irwin, D., Forster, B. B., \& Liddle, P. F. (2005). Dysfunction of a distributed neural circuitry in schizophrenia patients during a working-memory performance. Psychological Medicine, 35(2), 187-196.

Menon, V., Adleman, N. E., White, C. D., Glover, G. H., \& Reiss, A. L. (2001). Errorrelated brain activation during a Go/NoGo response inhibition task. Human Brain Mapping, 12(3), 131-143.

Mink, J. W. (2001). Neurobiology of basal ganglia circuits in Tourette syndrome: faulty inhibition of unwanted motor patterns? Advances in Neurology, 85, 113-122.

Muller, U., von Cramon, D. Y., \& Pollmann, S. (1998). D1- versus D2-receptor modulation of visuospatial working memory in humans. Journal of Neuroscience, 18(7), 2720-2728.

Nigg, J. T. (2005). Neuropsychologic theory and findings in attentiondeficit/hyperactivity disorder: the state of the field and salient challenges for the coming decade. Biological Psychiatry, 57(11), 1424-1435. 
Ozonoff, S., \& Jensen, J. (1999). Brief report: specific executive function profiles in three neurodevelopmental disorders. Journal of Autism and Developmental Disorders, 29(2), 171-177.

Ozonoff, S., \& McEvoy, R. E. (1994). A longitudinal study of executive function and theory of mind development in autism. Developmental Psychopathology, 6, 415431.

Ozonoff, S., \& Strayer, D. L. (1997). Inhibitory function in nonretarded children with autism. Journal of Autism and Developmental Disorders, 27(1), 59-77.

Parasuraman, R., Greenwood, P. M., Kumar, R., \& Fossella, J. A. (2005). Beyond heritability: Neurotransmitter genes differentially modulate visuospatial attention and working memory. Psychological Science, 16(3), 200.

Passamonti, L., Fera, F., Magariello, A., Cerasa, A., Gioia, M. C., Muglia, M., et al. (2006). Monoamine oxidase-a genetic variations influence brain activity associated with inhibitory control: new insight into the neural correlates of impulsivity. Biological Psychiatry, 59(4), 334-340.

Paus, T., sbreve, Zatorre, R. J., Hofle, N., Caramanos, Z., Gotman, J., et al. (1997). TimeRelated Changes in Neural Systems Underlying Attention and Arousal During the Performance of an Auditory Vigilance Task. Journal of Cognitive Neuroscience, 9(3), 392-408.

Petrides, M. (1994). Frontal lobes and behaviour. Current Opinion in Neurobiology, 4(2), 207-211.

Pietrzak, R. H., Mollica, C. M., Maruff, P., \& Snyder, P. J. (2006). Cognitive effects of immediate-release methylphenidate in children with attentiondeficit/hyperactivity disorder. . Neuroscience and Biobehavioural Reviews, 30, 1225-1245.

Posner, M. I., \& Peterson, S. E. (1990). The attention system of the human brain. Annual Review of Neuroscience, 13, 35-42.

Reuter, M., Ott, U., Vaitl, D., \& Hennig, J. (2007). Impaired executive control is associated with a variation in the promoter region of the tryptophan hydroxylase 2 gene. Journal of Cognitive Neuroscience, 19(3), 401-408.

Rinehart, N. J., Bradshaw, J., L., Moss, S. A., Brereton, A. V., \& Tonge, B. J. (2006). Pseudo-random number generation in children with high-functioning autism and Asperger's disorder: further evidence for a dissociation in executive functioning? Autism, 10(1), 70-85.

Risch, N., \& Rao, D. C. (1990). Genetic linkage and complex diseases, with special reference to psychiatric disorders. Genetic Epidemiology, 7(1), 3-16.

Robertson, I. H., Manly, T., Andrade, J., Baddeley, B. T., \& Yiend, J. (1997). 'Oops!': Performance correlates of everyday attentional failures in traumatic brain injured and normal subjects. Neuropsychologia, 35(6), 747-758.

Roesch-Ely, D., Scheffel, H., Weiland, S., Schwaninger, M., Hundemer, H. P., Kolter, T., et al. (2005). Differential dopaminergic modulation of executive control in healthy subjects. Psychopharmacology (Berl), 178(4), 420-430.

Rommelse, N. N., Altink, M. E., de Sonneville, L. M., Buschgens, C. J., Buitelaar, J., Oosterlaan, J., et al. (2007). Are motor inhibition and cognitive flexibility dead ends in ADHD? Journal of Abnormal Child Psychology, DOI: 10.1007/s10802007-9146-z. 
Ronald, A., Happe, F., Price, T. S., Baron-Cohen, S., \& Plomin, R. (2006). Phenotypic and genetic overlap between autistic traits at the extremes of the general population. Journal of the American Academy of Child and Adolescent Psychiatry, 45(10), 1206-1214.

Rubia, K., Russell, T., Bullmore, E. T., Soni, W., Brammer, M. J., Simmons, A., et al. (2001). An fMRI study of reduced left prefrontal activation in schizophrenia during normal inhibitory function. Schizophrenia Research, 52(1-2), 47-55.

Russo, N., Flanagan, T., Iarocci, G., Berringer, D., Zelazo, P. D., \& Burack, J. A. (2007). Deconstructing executive deficits among persons with autism: Implications for cognitive neuroscience. Brain and Cognition, 65(1), 77-86.

Rybakowski, J. K., Borkowska, A., Czerski, P. M., Dmitrzak-Weglarz, M., Skibinska, M., Kapelski, P., et al. (2006). Performance on the Wisconsin Card Sorting Test in schizophrenia and genes of dopaminergic inactivation (COMT, DAT, NET). Psychiatry Research, 143(1), 13-19.

Rybakowski, J. K., Borkowska, A., Czerski, P. M., Kapelski, P., Dmitrzak-Weglarz, M., \& Hauser, J. (2005). An association study of dopamine receptors polymorphisms and the Wisconsin Card Sorting Test in schizophrenia. Journal of Neural Transmission, 112(11), 1575-1582.

Sanders, J., Johnson, K. A., Garavan, H., Gill, M., \& Gallagher, L. (2007). A review of neuropsychological and neuroimaging research in autistic spectrum disorders: Attention, inhibition and cognitive flexibility. Research in Autism Spectrum Disorders, in press.

Schmidt, L. A., Fox, N. A., Perez-Edgar, K., Hu, S., \& Hamer, D. H. (2001). Association of DRD4 with attention problems in normal childhood development. Psychiatric Genetics, 11(1), 25-29.

Schmitz, N., Daly, E., \& Murphy, D. (2007). Frontal anatomy and reaction time in Autism. Neuroscience Letters, 412, 12-17.

Schmitz, N., Rubia, K., Daly, E., Smith, A., Williams, S., \& Murphy, D. G. (2006). Neural correlates of executive function in Autistic Spectrum Disorders. Biological Psychiatry, 59, 7-16.

Schneider, F., Habel, U., Reske, M., Kellermann, T., Stocker, T., Shah, N. J., et al. (2007). Neural correlates of working memory dysfunction in first-episode schizophrenia patients: an fMRI multi-center study. Schizophrenia Research, 89(1-3), 198-210.

Sesack, S. R., Hawrylack, V. A., Matus, C., Guido, M. A., \& Levey, A. I. (1998). Dopamine axon varicosities in the prelimbic division of the rat prefrontal cortex exhibit sparse immunoreactivity for the dopamine transporter. Journal of Neuroscience, 18, 2697-2708.

Silk, T., Vance, A., Rinehart, N., Egan, G., O'Boyle, M., Bradshaw, J. L., et al. (2005). Fronto-parietal activation in attention-deficit hyperactivity disorder, combined type: functional magnetic resonance imaging study. British Journal of Psychiatry, 187, 282-283.

Silk, T. J., Rinehart, N. J., Bradshaw, J., L., Tonge, B. J., Egan, G. F., O'Boyle, M. W., et al. (2006). Visuospatial processing and the function of prefrontal-parietal networks in Autism Spectrum Disorder: a functional MRI study. American Journal of Psychiatry, 163(8), 1440-1443. 
Slaats-Willemse, D., Swaab-Barneveld, H., de Sonneville, L., van der Meulen, E., \& Buitelaar, J. (2003). Deficient response inhibition as a cognitive endophenotype of ADHD. Journal of the American Academy of Child and Adolescent Psychiatry, 42(10), 1242-1248.

Smyrnis, N., Avramopoulos, D., Evdokimidis, I., Stefanis, C. N., Tsekou, H., \& Stefanis, N. C. (2007). Effect of schizotypy on cognitive performance and its tuning by COMT val158 met genotype variations in a large population of young men. Biological Psychiatry, 61(7), 845-853.

Stefanis, N. C., Os, J. V., Avramopoulos, D., Smyrnis, N., Evdokimidis, I., Hantoumi, I., et al. (2004). Variation in catechol-o-methyltransferase val158 met genotype associated with schizotypy but not cognition: A population study in 543 young men. Biological Psychiatry, 56(7), 510-515.

Stefanis, N. C., Trikalinos, T. A., Avramopoulos, D., Smyrnis, N., Evdokimidis, I., Ntzani, E. E., et al. (2007). Impact of Schizophrenia Candidate Genes on Schizotypy and Cognitive Endophenotypes at the Population Level. Biological Psychiatry, In Press, Corrected Proof.

Stins, J. F., Tollenaar, M. S., Slaats-Willemse, D. I., Buitelaar, J. K., Swaab-Barneveld, H., Verhulst, F. C., et al. (2005). Sustained attention and executive functioning performance in attention-deficit/hyperactivity disorder. Child Neuropsychology, 11(3), 285-294.

Stoltenberg, S. F., Glass, J. M., Chermack, S. T., Flynn, H. A., Li, S., Weston, M. E., et al. (2006). Possible association between response inhibition and a variant in the brain-expressed tryptophan hydroxylase-2 gene. Psychiatric Genetics, 16(1), 3538.

Szekeres, G., Keri, S., Juhasz, A., Rimanoczy, A., Szendi, I., Czimmer, C., et al. (2004). Role of dopamine D3 receptor (DRD3) and dopamine transporter (DAT) polymorphism in cognitive dysfunctions and therapeutic response to atypical antipsychotics in patients with schizophrenia. American Journal of Medical Genetics Part B: Neuropsychiatric Genetics, 124(1), 1-5.

Szöke, A., Schürhoff, F., Méary, A., Mathieu, F., Chevalier, F., Trandafir, A., et al. (2006). Lack of influence of COMT and NET genes variants on executive functions in schizophrenic and bipolar patients, their first-degree relatives and controls. American Journal of Medical Genetics Part B: Neuropsychiatric Genetics, 141B(5), 504-512.

Thapar, A., Holmes, J., Poulton, K., \& Harrington, R. (1999). Genetic basis of attention deficit and hyperactivity. British Journal of Psychiatry, 174, 105-111.

Thermenos, H. W., Goldstein, J. M., Buka, S. L., Poldrack, R. A., Koch, J. K., Tsuang, M. T., et al. (2005). The effect of working memory performance on functional MRI in schizophrenia. Schizophrenia Research, 74(2-3), 179-194.

Thoma, P., Wiebel, B., \& Daum, I. (2007). Response inhibition and cognitive flexibility in schizophrenia with and without comorbid substance use disorder. Schizophrenia Research, 92(1-3), 168-180.

Todd, R. D., Jong, Y. J., Lobos, E. A., Reich, W., Heath, A. C., \& Neuman, R. J. (2001). No association of the dopamine transporter gene 3' VNTR polymorphism with ADHD subtypes in a population sample of twins. American Journal of Medical Genetics, 105(8), 745-748. 
Townsend, J., Harris, N. S., \& Courchesne, E. (1996). Visual attention abnormalities in autism: delayed orienting to location. Journal of the International Neuropsychological Society, 2(6), 541-550.

Ucok, A., Alpsan, H., Cakir, S., \& Saruhan-Direskeneli, G. (2007). Association of a serotonin receptor $2 \mathrm{~A}$ gene polymorphism with cognitive functions in patients with schizophrenia. American Journal of Medical Genetics Part B: Neuropsychiatric Genetics, 144B(5), 704-707.

Valera, E. M., Faraone, S. V., Biederman, J., Poldrack, R. A., \& Seidman, L. J. (2005). Functional neuroanatomy of working memory in adults with attentiondeficit/hyperactivity disorder. Biological Psychiatry, 57(5), 439-447.

Vance, A., Silk, T. J., Casey, M., Rinehart, N. J., Bradshaw, J. L., Bellgrove, M. A., et al. (2007). Right parietal dysfunction in children with attention deficit hyperactivity disorder, combined type: a functional MRI study. Molecular Psychiatry, DOI: 10.1038/sj.mp.4001999.

Verte, S., Geurts, H. M., Roeyers, H., Oosterlaan, J., \& Sergeant, J. A. (2005). Executive functioning in children with autism and Tourette syndrome. Developmental Psychopathology, 17(2), 415-445.

Vijayraghavan, S., Wang, M., Birnbaum, S. G., Williams, G. V., \& Arnsten, A. F. (2007). Inverted-U dopamine D1 receptor actions on prefrontal neurons engaged in working memory. Nature Neuroscience, 10(3), 376-384.

Vink, M., Ramsey, N. F., Raemaekers, M., \& Kahn, R. S. (2006). Striatal Dysfunction in Schizophrenia and Unaffected Relatives. Biological Psychiatry, 60(1), 32-39.

Voeller, K. K. (2004). Attention-deficit hyperactivity disorder (ADHD). Journal of Child Neurology, 19(10), 798-814.

Wager, T. D., \& Smith, E. E. (2003). Neuroimaging studies of working memory: a metaanalysis. Cogn Affect Behav Neurosci, 3(4), 255-274.

Walter, H., Vasic, N., Hose, A., Spitzer, M., \& Wolf, R. C. (2007). Working memory dysfunction in schizophrenia compared to healthy controls and patients with depression: Evidence from event-related fMRI. NeuroImage, 35(4), 1551-1561.

Wang, K., Fan, J., Dong, Y., Wang, C.-q., Lee, T. M. C., \& Posner, M. I. (2005). Selective impairment of attentional networks of orienting and executive control in schizophrenia. Schizophrenia Research, 78(2-3), 235-241.

Wedenoja, J., Loukola, A., Tuulio-Henriksson, A., Paunio, T., Ekelund, J., Silander, K., et al. (2007). Replication of linkage on chromosome 7q22 and association of the regional Reelin gene with working memory in schizophrenia families. Molecular Psychiatry.

Weiss, G., \& Hechtman, L. (1993). Hyperactive Children Grown Up. New York: Guilford Press.

Weissman, D. H., Roberts, K. C., Visscher, K. M., \& Woldorff, M. G. (2006). The neural bases of momentary lapses in attention. . Nature Neuroscience, 9, 971-978.

Willcutt, E. G., Doyle, A. E., Nigg, J. T., Faraone, S. V., \& Pennington, B. F. (2005). Validity of the executive function theory of attention-deficit/hyperactivity disorder: a meta-analytic review. Biological Psychiatry, 57(11), 1336-1346.

Winterer, G., Musso, F., Konrad, A., Vucurevic, G., Stoeter, P., Sander, T., et al. (2007). Association of attentional network function with exon 5 variations of the CHRNA4 gene. Human Molecular Genetics. 
Winterer, G., Musso, F., Vucurevic, G., Stoeter, P., Konrad, A., Seker, B., et al. (2006). COMT genotype predicts BOLD signal and noise characteristics in prefrontal circuits. Neuroimage, 32(4), 1722-1732.

Wodka, E. L., Mahone, E. M., Blankner, J. G., Larson, J. C., Fotedar, S., Denckla, M. B., et al. (2007). Evidence that response inhibition is a primary deficit in ADHD. . Journal of Clinical and Experimental Neuropsychology, 29, 345-356.

Wright, M., De Geus, E., Ando, J., Luciano, M., Posthuma, D., Ono, Y., et al. (2001). Genetics of cognition: outline of a collaborative twin study. Twin Research, 4(1), 48-56.

Wykes, T., Reeder, C., \& Corner, J. (2000). The prevalence and stability of an executive processing deficit, response inhibition, in people with chronic schizophrenia. Schizophrenia Research, 46(2-3), 241-253.

Xu, H., Kellendonk, C. B., Simpson, E. H., Keilp, J. G., Bruder, G. E., Polan, H. J., et al. (2007). DRD2 C957T polymorphism interacts with the COMT Val158Met polymorphism in human working memory ability. Schizophrenia Research, 90(13), 104-107.

Yang, M. S., \& Gill, M. (2007). A review of gene linkage, association and expression studies in autism and an assessment of convergent evidence. International Journal of Developmental Neuroscience, 25, 69-85.

Yu, Y. W., Tsai, S. J., Hong, C. J., Chen, M. C., Yang, C. W., \& Chen, T. J. (2005). Association study of a functional MAOA-uVNTR gene polymorphism and cognitive function in healthy females. Neuropsychobiology, 52(2), 77-82.

Zabetian, C. P., Buxbaum, S. G., Elston, R. C., Kohnke, M. D., Anderson, G. M., Gelernter, J., et al. (2003). The structure of linkage disequilibrium at the DBH locus strongly influences the magnitude of association between diallelic markers and plasma dopamine beta-hydroxylase activity. American Journal of Human Genetics, 72(6), 1389-1400. 